\title{
Old Wine in A New Bottle: A Mediamorphosis Approach to Realising Nigerian Newspaper Potentials in an Online Era
}

\section{Abdullateef Mohammed ${ }^{1}$}

${ }^{1}$ National Open University of Nigeria

Plot 14, 16 Ahmadu Bello Way, Victoria Island 106104, Lagos, Nigeria

DOI: 10.22178/pos.74-9

LCC Subject Category:

ZA3038-5190

Received 21.08.2021

Accepted 25.09.2021

Published online 30.09.2021

Corresponding Author:

abmohammed@noun.edu.ng

(C) 2021 The Authors. This

article is licensed under a

Creative Commons Attribution

4.0 License @) (1)

\begin{abstract}
Information plays a crucial role in every society. The media of every society is responsible for transmitting assorted information to a wide range of diverse audiences through multiple channels, including newspapers, magazines, radio, television and of course, the new media (Internet). In a world where the Internet is becoming the fastest growing medium, technologies like computers and smartphones now enable people to access online news sites to read stories and share with others. Printed newspapers, particularly in Nigeria, have managed to thrive over the years, despite projections of its extinction by some communication experts. Using the Mediamorphosis theory as a base, this study takes readers on a journey to understanding the survival strategies employed by older mediums like the printed newspapers to weather the new media storm. Complimentarily, opinions of purposively selected respondents from Zaria, Kaduna state $(n=115)$ were analysed to determine the motives behind their preference of either online or hardcopy papers. Findings supported the view that in many settings still, there will be those who prefer to read the news the old way and that the new media, as at this time, mainly serve as a functional complement and not an outright replacement to traditional newspapers. The study recommends fact-checking, better marketing as strategies to bridge a credibility gap reported by respondents to exist in the use of both mediums.
\end{abstract}

Keywords: mediamorphosis; media convergence; newspaper readership; Nigeria.

\section{INTRODUCTION}

In a world where the Internet is becoming the fastest growing medium due to the convergence of computers and other telephony technologies, the mode of accessing news and information is experiencing a significant shift. Technological advancements have allowed people easy access to the news on multiple devices such as computers, smartphones, tablets, to mention but a few. These advancements have in one way or the other, influenced the patronage of printed newspapers.

Historically, the idea to record daily happenings or occurrences can be traced back to Caesar's reign in ancient Rome. At the time, stories of the day were written on a tablet and posted on a wall at the end of each senate meeting. This record or publication was called Acta Diurna. Since the information was posted on one wall (Baran, 1999) as cited in [20] informs no reliable measure of its total readership. Those who desired to read about the announcements of the day had to all converge at that particular wall where it was posted. It wasn't until the year 1620 that the one-page publication called the Corantos was published to carry the day's events in north-western Europe.

Furthermore, the 19th-century industrial revolution saw the newspaper industry's growth and expansion as copies changed style, structure, depth of coverage and reach. Urbanisation as a result of the industrial revolution equally contributed to literacy rate and widespread readership and patronage. Among these early papers was the New York Sun launched in 1833 by Benjamin Day, the New York Times launched in 1835 by James Gordon Bennett and the New York Tribune by Horace Greeley in 1841, thus marking the early days of the modern press.

In Nigeria, newspapers can be said to have begun in 1859. The first publication is credited to Rev. Henry Townsend, a European missionary who published the Iwe Irohin in Abeokuta, Nigeria. The full name of the publication was İwé İròhìn fún àwọn ará Egbá àti Yorùbá - simply meaning newspaper for the [2]. The author [20] writes that the success of Iwe Irohin paved way for other newspapers to follow, such as the Anglo African 
Newspaper published between 1863 to 1865 by Robert Campbell, The Nigeria Pioneer published by Kitoye Ajasa between 1914-1937, the African Messenger by Ernest Ikoli in 1921, the West African Pilot by Dr Nnamdi Azikiwe in 1937. Today, over 250 newspapers are in circulation in Nigeria, including Vanguard, The Guardian, The Punch, The Sun, ThisDay, The Nation etc [20].

With the invention of the World Wide Web by Tim Berners-Lee in 1989, the navigation and use of graphics on the Internet meant that the Internet could begin to function as a medium for mass communication. The Internet has, over the years, provided users multiple sources to access and disseminate information online through web pages such as websites, blogs, wikis etc. The author [16] stated some features of the Internet which, accordingly, are part of the reasons that give online newspapers an edge over their print counterparts. They include interactive potential, low degree of regulation, interconnectivity, ubiquity, low cost, and instantaneity, among others. He added that online newspapers could reduce the cost of production, especially when compared with their print counterparts. It has reduced the cost of publishing, overcome the constraint of distribution and circulation, gives instant interaction with the reader and made convergence possible. Now, readers could not only read newspapers but could as well listen and watch their contents at once. Internet sites supplement traditional "hard copy" sources in various ways, but they also provide bibliographic access to "hard copy" sources. We may now access online newspapers worldwide, enabling us to find information or track down an elusive title or reference. Once, we would have to dig into various guides of periodicals [24].

These advancements have, in one way or the other, influenced the readership habits of news consumers. While many researchers seem to approach the online-hardcopy discourse from a comparative perspective, this study approaches it from a collaborative view to chart the interdependent and interrelated interaction between both mediums.

\section{Literature review}

The author [3] observed that young people are future readers of the newspaper, but lure them to read them was a problem. Online news sites, according to him, might be the solution. Readership of online newspapers is an information sourcing and sharing activity [6]. The author (Pavlikas, 2001) as cited in [18] stated that in the rapidly changing world of online publishing, where newspapers around the world increasingly operate web versions of their hardcopy, more and more people with a means of connecting to networked computers will turn to the Internet for news, the number of newspapers online would increase substantially.

The researcher [10] found that newspapers in Italy have gone online to attract young and adult audiences who refuse to spend money on hardcopy. Authors [14] reaffirm that the amount of time spent watching television, talking on the telephone, and reading hard copy newspapers decreases due to using online media. According to [25], online news outlets have slowly begun to usurp the place that older media occupied, which was the primary source of information. Hence, with the advent of this new technology, print newspaper circulation and readership are significantly declining every day [25]. Studies continue to show a decline in print newspaper readership even in developed countries of Europe and North America that many newspapers have either ceased publication entirely or shifted to onlineonly editions [11]. The author [7] thinks that some have attributed this overall decline to increased mobility of Americans, the increase in single-person households, more expensive subscription and per-copy prices, a general decline in the literacy of young people and competition from other media, especially the Internet. According to [16] there has been a gradual worldwide decline in newspaper readership over the last decade, despite the increase in literacy and with the rise of the Internet probably playing some part. According to a study by [22], the share of Americans who prefer to get their news online is growing. In 2018, about $34 \%$ of U.S. adults said they preferred to get news online, whether through websites, apps or social media, an increase to the $28 \%$ that said the same in 2016. In Nigeria, similar studies such as [23] which examined the level of online newspaper reading in Nigeria, found that the majority (78\%) of Nigerians read online newspapers, concluding that online newspaper is gaining acceptability among Nigerians.

In contrast to the above positions is (Abplanalp, 2005) cited in [24] who found that public's commitment to the print format seems to be stronger than expected; based on a survey he conducted to study print competitiveness in the marketplace. In a study by [17], students asked about the San 
Jose Mercury News published online were reported to have said "the electronic newspaper was unappealing to browse leisurely, inappropriate for all news material, uncomfortable to travel through, not preferable over traditional newspaper and more difficult to read than a traditional newspaper" [17]. Collaboratively, the Online Publishers Association in 2004 conducted similar research on 25,852 visitors of forty-one main U.S. news sites and found that in a 2-to- 1 margin, online media were found to be deemed less pleasing, less friendly, and less pleasurable than offline media [21]. Their findings align with that of [21], whose respondents equally preferred print newspaper and rated it higher than other media platforms.

Weighing in from a different perspective is (Biggs, 2006) as cited in [24] who argued that online publication isn't about old media versus new media; it's about cheap media versus expensive media. Biggs write-ups look at a newspaper from the cost perspective to discuss both online and hardcopy. From a media interdependence point of view, (Rosengren, \& Windahl, 1989; Stempel et al., 2000) as cited in [24] suggested that online media are a "functional supplement to traditional media instead of a replacement or displacement mechanism."

These contradictory findings have given rise to diverse opinions about the future of new and conventional newspapers, and this study attempts to shed light on the questions surrounding this issue by exploring the link between traditional newspapers and the use of online news platforms, as explained in the Fiddler's mediamorphosis theory of communication.

Background of Mediamorphosis Theory. Mediamorphosis' was coined by Roger Fiddler in 1990 but propounded as a theory in 1997 by the same scholar. Extensive explanation of the theory is found in [8]. According to [8], mediamorphosis is "the transformation of communication media, usually brought about by the complex interplay of perceived needs, competitive and political pressures, and social and technological innovation". This term, also known as 'digital metamorphosis' is the transformation from oral literature to digital. According to [8], the mass media is constantly changing, but contextual and critical analysis of the change was yet to be done. The theory is aimed at providing a comprehensive framework that charts the evolution and interaction between media forms.
Related Assumptions of the Theory:

1. New media do not arise instantaneously or are devoid of external influence. Instead, new media are linked to old ones. This means that every news platform must have evolved from a pre-existing medium of communication. For instance, E-editions of newspapers are simply duplications of the printed copies in digital format. The idea behind these printed copies could also be traced back to the handwritten newspaper Acta Diurna.

2. When new media emerge, the old ones do not die; they continue to evolve, adapt, and retain the traits from the domain they evolved. Simply put, new media emerge gradually from the metamorphosis of the old media.

3. Rather than doing away with older forms, new forms of communication have instead diverged and added to the media mix, and this leads to an increase in media consumption

From the stated assumptions, we can gather that the theory under discussion encourages examining all media forms as members of an interdependent system. Thus, there is a relationship that exists among the past, present and evolving forms.

Strengths of the Theory: 1) Mediamorphosis explains how new and old media come together to enhance effective communication. For example, social media platforms like Twitter, Facebook and YouTube influence the development of existing forms such as newspapers and books. 2) The theory encourages old media to adapt to new trends.

Weaknesses and Criticisms of the Theory: 1) Delayed adoption: To some degree, mass user migration contradicts Fiddler's 20-30 years adoption principle. Fiddler has predicted that for a new media to be adopted by the mass audience, it must take at least 20-30 years. However, this prediction is faulty because the present acceleration for adopting online social media outstrips the 20-30year time frame theorised by Fiddler for widespread application and commercialisation success of new technology. 2) Undefined terms: The theory does not identify the new media and what is referred to as the old. What may be considered new today might be old tomorrow.

Significance of Mediamorphosis Theory to Online/Hard-copy Interplay and Patronage. The propounder of the theory, Roger Fiddler, stated that there could be a unified way of thinking about the technological evolution of communication media by studying the communication 
media as a whole. For instance, centuries ago, there was nothing like the mass media as we have it today. Still, due to technological development, print media came into being, followed by electronic media (radio, television) then Internet. The new media emerged to update and upgrade the old media. In this sense, we can argue that the online news sites mainly improve upon the hard copied newspapers that were previously in vogue. The new media did not arise spontaneously or independently but due to gradual improvements on either an old medium or its idea. This historical pattern of change within the communication system prompted Fiddler to state that the emergence of a new medium or technology does not mean the end or death of an existing old medium. This assertion is true because mainstream media still enjoys heavy patronage globally despite the emergence of podcasts, blogs, YouTube, and other live audio-visual streaming platforms.

Compared with the Darwinian theory of evolution, Fiddler explains that new media forms emerge to meet the changing environmental needs. Still, the new ones influence the older ones, which tends to survive. For example, the decline in hardcopy newspaper patronage due to the advent of the Internet prompted some experts to predict the death of the newspaper industry. Yet, in contrast, newspapers adapted to internet technology. Likewise, print media (newspapers, magazines, books and so on) have made significant transformations over the past few years due to new technologies that allow for media convergence. With the new media (Internet), we can watch online TV news; listen to the radio, read online versions of newspapers, books and magazines. This is because every personal computer or mobile smartphone offers users the ability to blend texts and still images into audio and video clips and the opportunity to conveniently delve into the global network and vast access stores of textual and audio-visual information.

In the same way that it takes a long time for an animal to be fully matured, the development of the media takes time. Communication technologies would not have been possible if the birth of each new medium had resulted in the death of the old medium.

What print publishers are doing to stay in business? Several studies have been put forth to discuss some survival models employed by publishers to remain in business. A 2006 survey report published by the World Association of
Newspapers and News Publishers (WAN-IFRA) shows other newspaper publishers' business models. They include:

Outsourcing: Their findings indicate that many publishers now outsource nonstrategic activities such as telephone marketing, pre-press, printing, transport, information technology, catering, and security, leaving out only their editorial activities and advert sales.

Cooperation Activities: In efforts to reduce production, this report indicated that most publishers indicated that they were engaged in more than one type of cooperation activity with other media partners. Such as Cooperation in advertising, content generation and distribution, printing, content and technology investments.

Mergers and Acquisitions: The report also indicated that publishers were involved in merger and acquisition activities.

Furthermore, economic scholar [15] equally highlighted the following survival strategies adopted by publishers to include:

Information Technology: The possibility for reusability of information across customers has increased due to Information Technology. This allows publishers to offer a range of products and services to their customers, thus, facilitating some competitive advantage. In addition, new technologies such as the Internet and online subscription services make it possible to combine old and new media into one product with an additional element that was missing in the earlier markets; interactivity. Interactivity allows for greater personalisation of relationships between customers and publishers. Among the services publishers could offer to include interactive forums, searchable news archives, online transactions, up-to-theminute information, and audio/video content presentations. However, the author [15] noted that to use these technologies in a competitive way, substantial investments in capital and expertise are required in most cases.

Marketing and reputation: The author [15] found that rigorous marketing enlarges the readership of newspapers as it helps create a brand image and loyalty of customers. Image and loyalty are related to the notion of 'reputation' [15]. Building up a good business reputation is through consistent policy, marketing, and highly qualified products and services. News deals with facts. Therefore, newspaper publishing companies offer products (news contents) that may make or mar their 
reputation and reliability. Therefore accuracy, objectivity and balance play critical roles in building a good brand reputation. Furthermore, publishers get to leverage or capitalise on their reputation as bargaining power to negotiate lower prices for their production inputs or diversify into several unrelated and related businesses.

Innovations: Innovation gives companies temporally monopolies because they have no competitors on the same playing field until a company duplicates or betters the innovations or products. These temporal innovations are essential for the publishing companies because they can protect or increase the market share. For instance, they are diversifying into magazine production and other print products such as booklets, brochures, business cards, calendars, catalogues, cards, envelopes, flyers, tags, labels, notepads, posters, banners, diaries, jotters, etc.

Authors [13] presented some currently obtainable business models that modern-day newspaper publishers around the world adapt to weather the new media storm. They include:

Advertising e-business model: Today, advertisements such as banner ads or sponsored links are featured on many news websites. This model is most effective when the amount of traffic to the website is large or specialised.

Subscription model \& utility model: Newspaper publishers charge certain fees to subscribe to content with the subscription model. Options to readonly or download a part or all of the content could be made subject to the amount paid.

Community Business Model: Newspaper publishers could go on to create discussion forums for their readers. According to [13], since the community model is based on user loyalty, users develop deeper relationships with current readers, potential readers, and commercial customers who are emotionally invested in the online community. With this model, revenue can be based on selling ancillary products and services, or revenue could be tied to contextual advertising and subscription for premium services [13].

Brokerage: The scholar's [13] propose that Industries such as print publishing industries could adopt Rappa's brokerage model for web-based enterprises, where a newspaper, by capitalising on its archives, equipment, and brand image, could act as a broker bringing buyers and sellers together and facilitating transactions.
In addition to all the above, authors [13] further proposed how publishers can further harness native and new e-commerce models. They include finding ways to monetise archive information beyond users paying for access to old articles, developing profile habits and interests based on IP address of users and offer to advertisers for direct marketing, create paid tools useful to readers business needs such as simple accounting software and financial budgeting tools, offer online video rental services, music downloads, and the likes. Lastly, provide website hosting and other internet services for businesses; allow for the upload of press releases to the particular business area of site and charge companies a fee for service [13].

These strategies and more show why the newspaper business may not be going extinct as many have projected.

\section{METHODOLOGY}

For broader insights into this topic, this study purposively selected 115 residents of the Samaru community in Zaria, Kaduna state. It adopted the survey research design to systematically sample respondents' opinions who consume online or hardcopy news stories and are willing to partake in the survey. Validity was ensured by subjecting the questionnaire instrument used to review and vetting by other researchers. Descriptive statistics involving tables, charts, percentage distributions and frequency patterns are used to present the outcome of the responses from the questionnaires.

\section{RESULTS AND DISCUSSION}

Table 1 - Bio-data presentation

\begin{tabular}{|l|r|r|}
\hline \multicolumn{1}{|c|}{ Variable } & Frequency & \multicolumn{1}{c|}{$\%$} \\
\hline Gender & $\mathbf{1 1 5}$ & $\mathbf{1 0 0 . 0}$ \\
\hline Male & 73 & 63.5 \\
\hline Female & 42 & 36.5 \\
\hline Age & $\mathbf{1 1 5}$ & $\mathbf{1 0 0 . 0}$ \\
\hline $15-24$ & 16 & 14.0 \\
\hline $25-34$ & 6 & 5.0 \\
\hline $35-44$ & 31 & 27.0 \\
\hline $45-54$ & 34 & 30.0 \\
\hline $55-64$ & 24 & 20.0 \\
\hline $65 \&$ above & 4 & 3.5 \\
\hline Education & $\mathbf{1 1 5}$ & $\mathbf{1 0 0 . 0}$ \\
\hline Diploma & 22 & 19.1 \\
\hline
\end{tabular}




\begin{tabular}{|l|r|r|}
\hline \multicolumn{1}{|c|}{ Variable } & Frequency & \multicolumn{1}{c|}{$\%$} \\
\hline HND/BSC & 42 & 36.5 \\
\hline Postgraduate & 51 & 44.3 \\
\hline Marital Status & $\mathbf{1 1 5}$ & $\mathbf{1 0 0 . 0}$ \\
\hline Single & 9 & 7.8 \\
\hline Married & 102 & 88.7 \\
\hline Divorced & 4 & 3.5 \\
\hline Do you read news stories? & $\mathbf{1 1 5}$ & $\mathbf{1 0 0 . 0}$ \\
\hline Yes & 115 & 100.0 \\
\hline No & 0 & 0 \\
\hline Major News Source / & $\mathbf{1 1 5}$ & $\mathbf{1 0 0 . 0}$ \\
Preference & 66 & 57.4 \\
\hline Online & 49 & 42.6 \\
\hline Hard-copy & &
\end{tabular}

Data from the above table indicates that there are more males $(63.5 \%)$ than female $(36.5 \%)$ respondents for this study, and the highest of all the age groups are 35-44(27\%) and 45-54 (30\%) respectively. Virtually all the respondents are educated, with the majority (44\%) being postgraduate degree holders. The data also indicates that 66 respondents (57.4\%) prefer accessing and reading news online instead of the 49 others (42.6\%) who prefer Hard-copy. This reaffirms the study by (Pavlik, 2001) as cited in [18], which states that in the rapidly changing world of online journalism,

where newspapers around the world increasingly operate web versions of their hardcopy, more and more people with a means of connecting to networked computers turn to the Internet for news. Almost every Nigerian possesses mobile phones, laptops, iPad and other devices that enable internet browsing.

Careful analysis of the retrieved questionnaires indicated that young and mid-aged people within the age range of 25-45 years constitute the significant consumers of online news stories, while those above 45 years of age prefer hardcopy. This may be attributed to the high rate of sophisticated Internet enabling devices that the young and midaged generations make use of.

The findings corroborate [10], who stated that newspapers go online to attract young and adult audiences who refuse to spend money on the hardcopy.

\section{What reasons are behind users' preference and patronage of online news?}

There are several obvious reasons why newsreaders may prefer to access and read news online. Our 66 respondents (57.4\%) who indicated a preference for online news were asked to state why. The below figure 1 contains their responses:

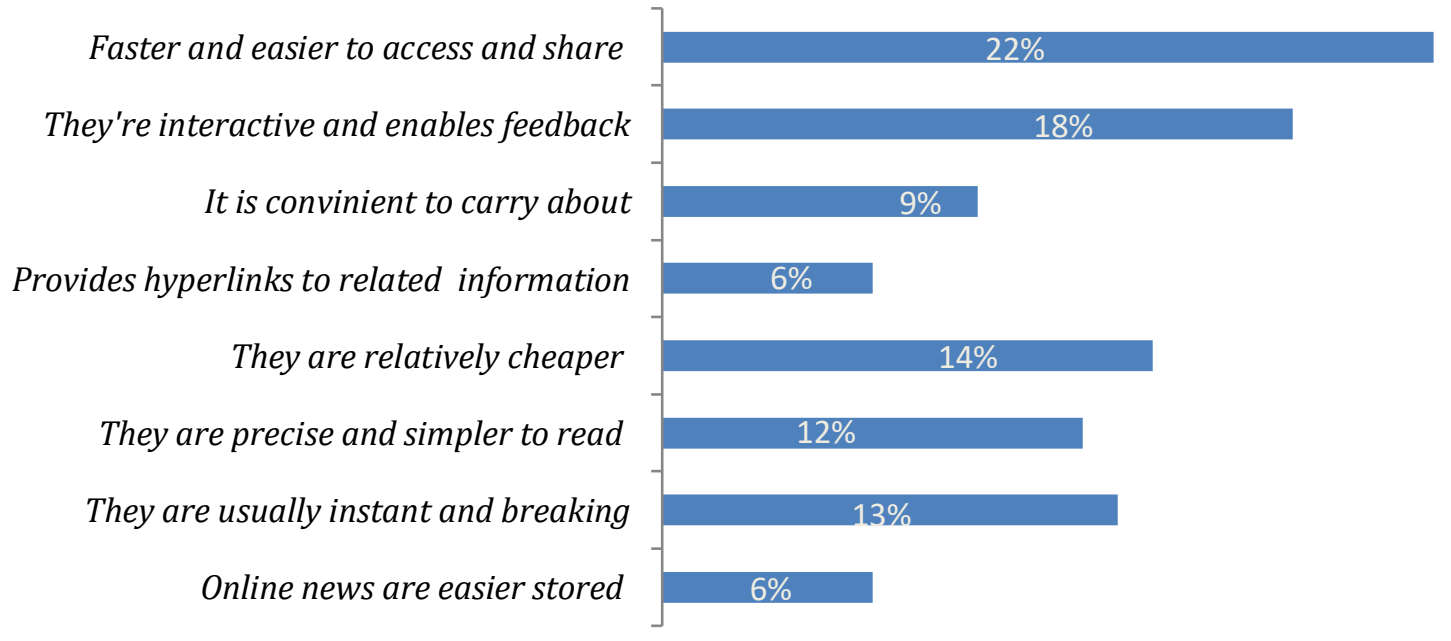

Figure 1

As can be seen above, some 15 respondents $(22 \%)$ consider and read online news because of its ease of access, while 12 (18\%) prefers online news because it is interactive and enables feedback. This is in line with (Khan, 1999) cited in [24] who argues that given the increasing use of internet technology globally, the development of online news as a new way of mass communication has introduced a new, efficient and fast way of disseminating and accessing news stories. This finding also confirms that of corroborates the study by [9]. Furthermore, online news media is preferred to the traditional newspaper because it is interactive and provides searchable features and the ability to cross-reference through hyper-linking and provides other multimedia features. 
Also, from the table, six respondents (9\%) prefer online news due to its convenience, while four others $(6.1 \%)$ prefer it because it provides links to other information. According to a study by [22], Online news is valued most for headlines and convenience, not detailed, in-depth reporting. This means that while hardcopy papers are preferred because of their in-depth and detailed reports, online news is valued for its ability to provide breaking news headlines, thus corroborating the eight respondents (13\%) who prefer online news simply because it is instant and breaking.

Another vital factor that influences the decision to access the Internet for news is cost. This is why some nine respondents $(13.6 \%)$ prefer online news because it is relatively cheap to get. This very much tallies with the findings of Biggs (2006), who views that online publication isn't

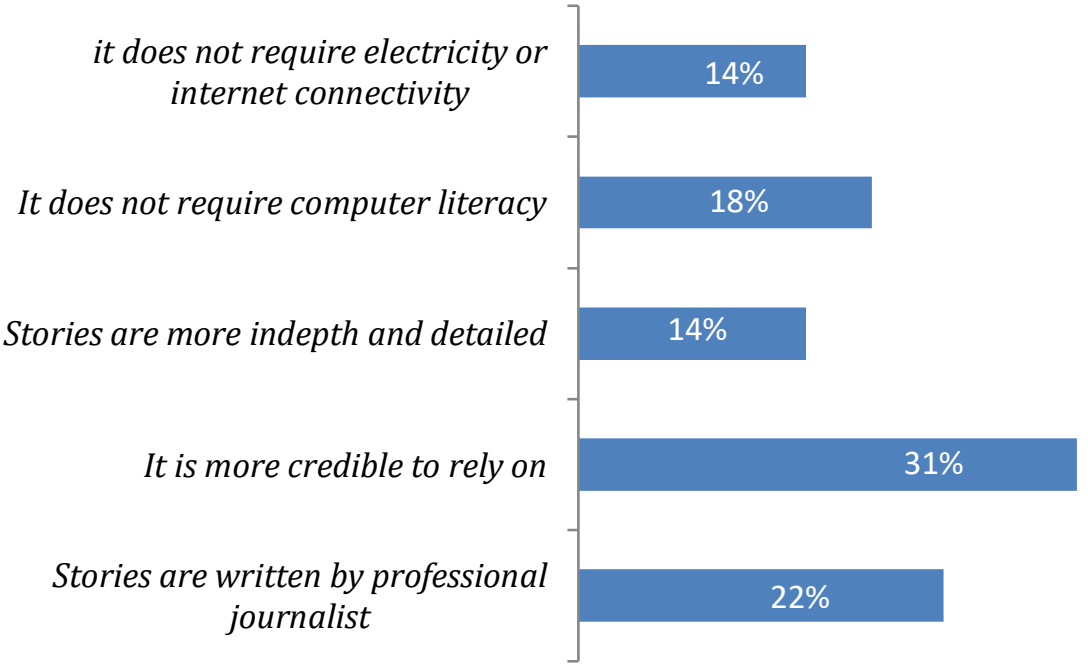

Figure 2

As can be seen in figure 2 above, 11 respondents $(22 \%)$ prefer hardcopy because it is more stories therein are in most cases prepared by certified journalists who investigate, gather and write their stories in conformity with the ethical code of conduct of their profession as well as the editorial policies of their organisations. This may not be the case for some online news sites, as ill-trained or unprofessional news writers manage some. Also, from the figure, 15 others (30.6\%) prefer it because it is more credible to rely on. This is particularly true because the news stories that emanate from hardcopy reflect the reputation and integrity of the producing firms, which in most cases are firms licensed and registered by the country's laws. Furthermore, some seven respondents (14.3\%) prefer hardcopy because its stories are about old media versus new media; it's about cheap media versus expensive media. For example, in Nigeria, the price of a single newspaper ranges from N200 to N500 depending on the location it is being sold, while an internet data bundle of N100 on a mobile phone is sufficient to read news stories from at least ten different news websites.

\section{What are the reasons behind users' prefer- ence and patronage of hardcopy news?}

Just as some prefer online copies, some people still prefer to read printed papers for various reasons, chief among them reasons being accuracy and credibility. Therefore, our respondents who prefer to read hardcopy (42.6\%) were asked to state the reason for their choice. The below figure 2 contains the responses they gave: more in-depth and detailed, nine others (18.4\%) prefer it because reading newspapers does not require computer literacy. In comparison, the remaining seven respondents (14.3\%) prefer it because reading newspapers does not require electricity or internet connectivity. Given the epileptic power situation of Nigeria coupled with poor internet networks in many communities in Nigeria, it becomes understandable that some will prefer hardcopy papers that don't require the availability of any of those above to be used.

\section{Will hardcopy papers go extinct or be replaced by online news sites?}

Although $57.4 \%$ of the respondent for this study responded in favour of online news, there is still a substantial (42\%) who prefer traditional newspapers. Of course, this implies in any setting; still, 
there will always be those that value hardcopy more. Thus, the online news as we have it today is not yet a replacement for traditional newspapers; instead, they play complementing roles. Corroborating this claim is [4], who wrote that "online media are a functional supplement to traditional media instead of a replacement or displacement mechanism". Also, according to tenets of the Mediamorphosis theory used as a framework for this study, when new media emerge, the old ones do not die; they continue to evolve and adapt and retain the traits from the domain from which they evolved. Therefore, following some of the survival strategies by publishers earlier discussed, traditional publishers could always consider outsourcing, investment in information technology, rigorous marketing, expansion into other print production and embracement of new e-commerce models as measures to stay in business.

\section{CONCLUSIONS}

The need to communicate has brought in several innovative news formats and devices to access them. Online news platforms can be classified among these innovative means, and it has played a part in shaping human reality. According to Marshall McLuhan, we shape our tools, and our tools shape us. This implies that man designed these technologies, such as the Internet and its digital devices. Now the usage of these technologies has over time shaped and influenced our manner of doing things. With the advent of the Internet, online news has become a vital communication instrument to society. However, this research work has shown that although online news has affected the patronage of traditional newspapers, there are various ways in which publishers can harness the new media technologies to maintain their brand and relevance and maximise profit.

This study will not be complete without providing some measures that publishers could adopt as strategies to improve readership.

1. Online news editors should ensure contents appeal not only to the younger readers but to everyone in general. The age-preference gap as observed in this study must be bridged.

2. One of the primary motivations for readership online is because news is updated faster. Therefore, all and not just some of the hardcopy news publishers must own and operate a complimentary online news website and treat it as part and parcel of their newspaper outfit to limit themselves to daily publications only.

3. A holistic approach should be taken towards the quality of news reportage and services rendered to readers.

4. Reading online is very dynamic. Therefore, a regular audience survey must be carried out to ascertain the different target audiences' changes to be implemented.

\section{REFERENCES}

1. Abplanalp, A. (2005). China's print sector gears up for a more challenging future. Media Asia, 14.

2. Akpobo, 0. (2012). Historiography of The Print Media: A Global-Cum-Nigerian Perspective. Journal of African Studies, 1(1), 1-9

3. Baran, S. J. (2004). Introduction to Mass Communication: Media, Literacy and Culture. Boston: McGraw-Hill Books.

4. Chan, J. K.-C., \& Leung, L. (2005). Lifestyles, reliance on traditional news media and online news adoption. New Media \& Society, 7(3), 357-382. doi: 10.1177/1461444805052281

5. Chyi, H. I., Lee, A. M. (2012). Will the Internet Disrupt? A Reality Check on Format Preference for Traditional and Digital Content Across Five Media. Retrieved from https://www.academia.edu/3448049/Will_the_Internet_Disrupt_A_Reality_Check_on_the_Perfo rmance_of_Online_and_Traditional_Formats_Across_Five_Media

6. De Waal, H., Schonebach, J., Lauf, E. (2006, January). Online Newspapers: A Substitute for Print Newspapers and other Information Channels? Retrieved from https://www.researchgate.net/publication/284106379_Online_newspapers_A_substitute_or_co mplement_for_print_newspaper_and_other_information_channels_Communications 
7. Dominick, J. R. (2011). The Dynamics of Mass Communication: Media in Transition. New York: McGraw-Hill.

8. Fidler, R. (1997). Mediamorphosis: Understanding the New Media. Thousand Oaks: Sage.

9. Flynn, R. J., \& Tetzlaff, W. H. (1998). Multimedia - An introduction. IBM Journal of Research and Development, 42(2), 165-176. doi: 10.1147/rd.422.0165

10. Fortunati, L. (2005). Mediatization of the Net and Internetization of the Mass Media. Gazette (Leiden, Netherlands), 67(1), 27-44. doi: 10.1177/0016549205049177

11. Franklin, B. (2008). The future of newspapers. Journalism Studies, 9(5), 630-641

12. Geiger, A. W. (2019, September 11). Key findings about the online news landscape in America. Retrieved from https://www.pewresearch.org/fact-tank/2019/09/11/key-findings-about-theonline-news-landscape-in-america/

13. Johnson, R., \& Gutiérrez, A. (2010). Reinventing the business model of the newspaper industry: electronic business models and the newspaper industry. Retrieved from https://www.divaportal.org/smash/get/diva2:832292/FULLTEXT01.pdf

14. Kayany, J. M., \& Yelsma, P. (2000). Displacement Effects of Online Media in the Socio-Technical Contexts of Households. Journal of Broadcasting \& Electronic Media, 44(2), 215-229. doi: 10.1207/s15506878jobem4402_4

15. Kranenburg, H. (2004). Strategic Options for the Newspaper Publishing Companies. Retrieved from https://core.ac.uk/download/pdf/6750553.pdf

16. McQuail, D. (2010). McQuail's Mass Communication Theory (6th Ed.) London: Sage Publications.

17. Mueller, J., \& Kamerer, D. (1995). Reader Preference for Electronic Newspapers. Newspaper Research Journal, 16(3), 2-13. doi: 10.1177/073953299501600301

18. Ndangam, L. N. (2008). Cameroon's Diaspora and online news publishing. New Media \& Society, 10(4), 585-604. doi: 10.1177/1461444807086476

19. Nwodu, L. C. (2006). Journalism practice: News, aesthetics, ethics and laws. Enugu, Nigeria: Rhyce Kerex.

20. Nwodu, L.C., Iroajugh, A., \& Iroajugh, Ch. O. (2013). Mass communication and national development. Retrieved from https://nou.edu.ng/sites/default/files/2017-03/MAC\%20316.pdf

21. Online Publishers Association. (2004). Multi-Channel Brands: Attitudinal and Usage study. Retrieved from

http://onlinepubs.ehclients.com/images/pdf/140_W_opa_multichannel_media_brand_study_no v03.pdf

22. Pew Research Center. (2006, July 30). Online Papers Modestly Boost Newspaper Readership. Retrieved from https://www.pewresearch.org/politics/2006/07/30/online-papers-modestlyboost-newspaper-readership/

23. Sani, I. (2017). Preference between Online Newspapers and Conventional Newspapers among Students of Faculty of Social Sciences, ABU, Zaria.

24. Talabi, F. (2009). Influence of Internet on newspaper readership a comparative study of on-line and hard-copy newspaper readership in port-harcourt metropolis. Retrieved from http://www.unn.edu.ng/publications/files/images/TALABI,\%20FELIX\%200LAJIDE.pdf

25. Uwakwe, O. (2010). Introduction to Mass Communication in the Digital Age. Onitsha.

26. WAN-IFRA. (2006). Business Models of Newspaper Publishing Companies. Retrieved from http://www.robertpicard.net/PDFFiles/IFRAbusinessModels.pdf 